\title{
金合欢根很类蓸体周膜融合及其袁老 解离的亚显微结构研究
}

\author{
吴以德黄维南卓仁松 \\ （福建亚热带植物研究所，圆门）（福建农学院, 䄄州）
}

世界上生物固氮效力以豆科植物最高. 在细胞结构与功能研究中, 根疼菌和宿主植物间 的关系是一个复杂过程. 虽然这一由根瘤菌侵入根毛后, 在宿主细胞质中发育形成固锁类菌 体的过程, 已有不少的报道 ${ }^{[1-7]}$. 但对整个共生结构变化的了解仍然相当肤浅. 1983 年 Sutton ${ }^{[8]}$ 曾将一百多年来有关根瘤菌发育和衰老的研究 423 篇论文进行了专门性综述. 其中 尚无类菌体周膜融合与解离过程的研究. 本工作是继文献 [9] 报道热带豆科根瘤结构研究的 基础上,进一步探讨金合欢属的两种树木根瘤发育过程中,未成熟类菌体和成熟类菌体周膜融 合前后形态特征以及衰老类菌体周膜崩解的变化.

\section{材 料与 方 法}

\section{1. 根瘦材料}

采自栽培于厦门本所红壤土、多年生苏门答腊金合欢 [Acacia glauca (L.) Moench] 和有 刺金合欢 (Acacia farnesiana Willd) 根系上. 由于终年不断结瘦, 根瘤发育年龄很不整齐, 在 外形、大小不相等的情况下, 选择开花前最大量发育的成熟根癭类型, 作为电镜检验样品 ${ }^{[6]}$.

\section{2. 方法步虽}

切取有效根瘤的中心部分红色组织 ${ }^{[9,10]}$, 约 1 毫米见方小块, 用 $2.5-3.0 \%$ 戊二酫和 $1.0 \%$ 锇酸固定, 经各级乙醇脱水, Epon812 包埋. LKB-2088V 型超薄切片机上玻璃刀切片, 厚度约 500 埃,醋酸铀和柠檬酸铅染色, 放在 JEM-100CX 电子显微镜观察并摄影.

\section{结 果}

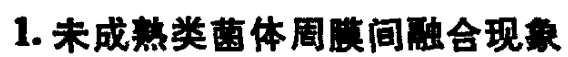

未成熟类菌体细胞外形较小,常见有圆球形、椭圆形和长椭圆形.此时期细胞质浓密、染 色深而且均匀. 嗜锇酸颗粒 (糖原)分布细胞内. 类菌体周膜间隙旺现电子透明区域 (图 1 3).

苏门答腊金合欢 (图 3) 和有刺金合欢 (图 1-2) 类菌体周膜融合时，一边的膜表面凸起， 另一边凹陷而形成对位肪合 (图 1-3 中 1). 但这仅是一种接触连络的方式, 尚未真正起融合 作用. 随后可看到两膜间穿通(图 1-3 中 3), 并不断扩大形成新的融合体. 扩展的新膜内类 菌体群聚在一起, 使菌细个体数目迅速增多. 图 1-3 中所示, 不同种类根瘤未成熟类菌体周

本文 1985 年 7 月 15 日收到. 


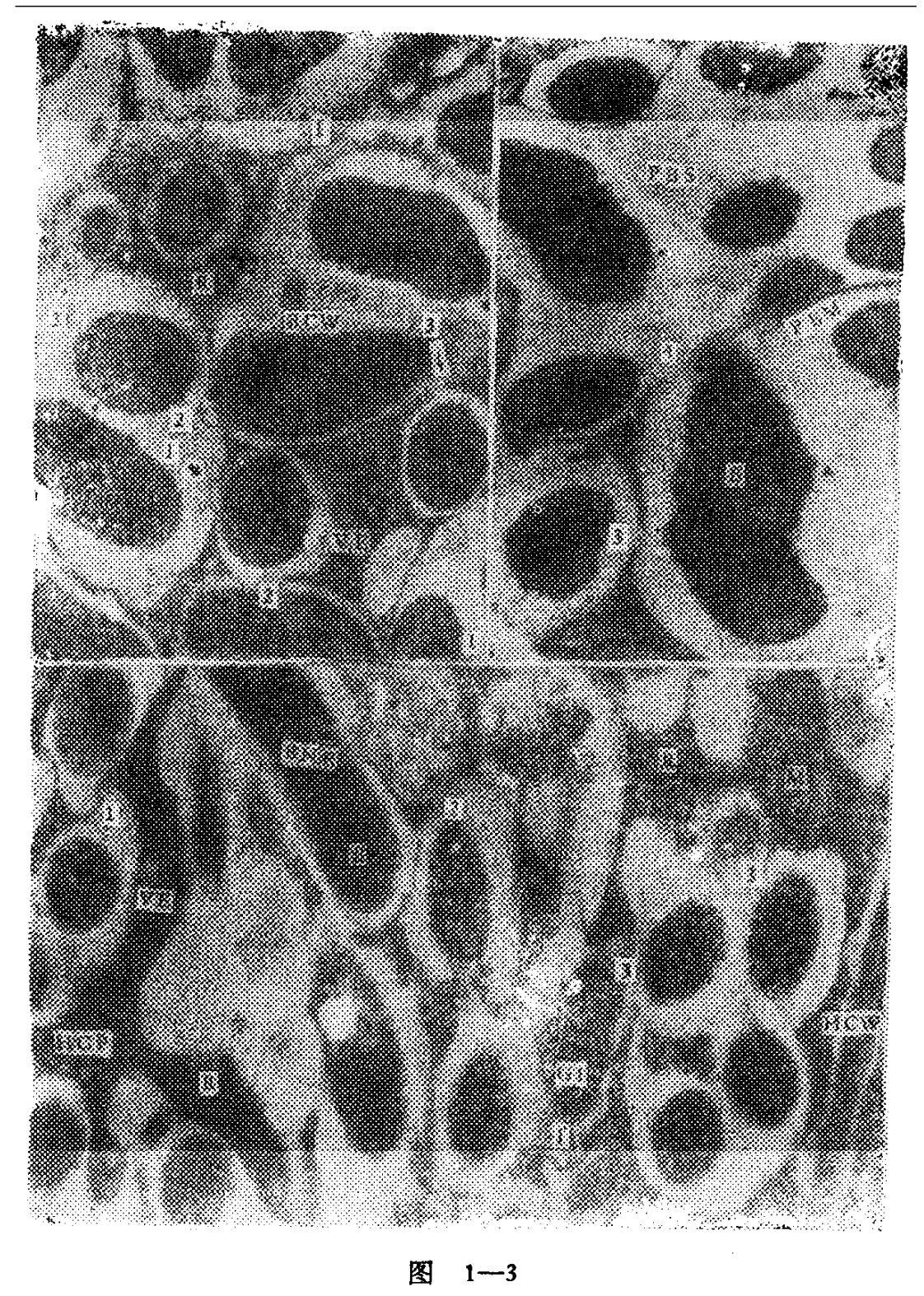

1一2. 类菌体周膜的融合反应, 在侧膜多处与相邻膜形成凹凸嵌合 (1), 两膜进一步接近 (2), 在膜中间 融合穿通 (3) 以及融合膜范围扩大 (4). 图 $1 \times 28,000$ ，图 $2 \times 37,800 ; 3$. 类菌体周膜自視融合. 先 在两膜间形成凹凸对位相诺 (1)，两膜紧密贴近 (2)，膜间部分融合穿通 (3). $\times 28000$

因 1-3 为末成就类菌体的电镜照片，其中图 1-2 为有刺金合欢. R. 核结体; BCW. 类菌体细胞壁;

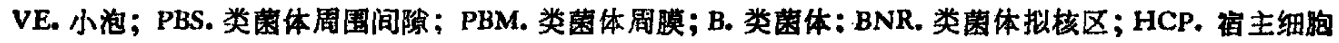
质; M. 线柆体; HCW. 宿主细胞䀈；Gl. 糖原

膜边缘与相邻膜间,可多处同时发生不同阶段的融合过程. 如 1 为凹凸柆合; 2 为两膜紧密贴 近; 3 为膜中间穿通融合；4为哑呤状融合体阶段.

\section{2. 成熱类菌体周膜而合过程}

成熟类菌体外形更大些,在细胞内有聚 $\beta$-羟基丁酸 (PHB) 累积增多, 出现形状大小不定. 电子透明的颗粒体,染色不均匀. 苏门答腊金合欢类菌体周膜融合有一个连续变化的过程。 为便于说明,可分为五个动态阶段的形态特征进行描述(图 4-6):

（1）膜间对位相宛: 在相邻膜之间接触中,最先可看到一方的膜表面延伸出指状(类似伪 足)凸起,与对位膜凹陷构成相互嵌 (见图 4 右侧1白箭头所示),两膜之间出现“不对称型”相 

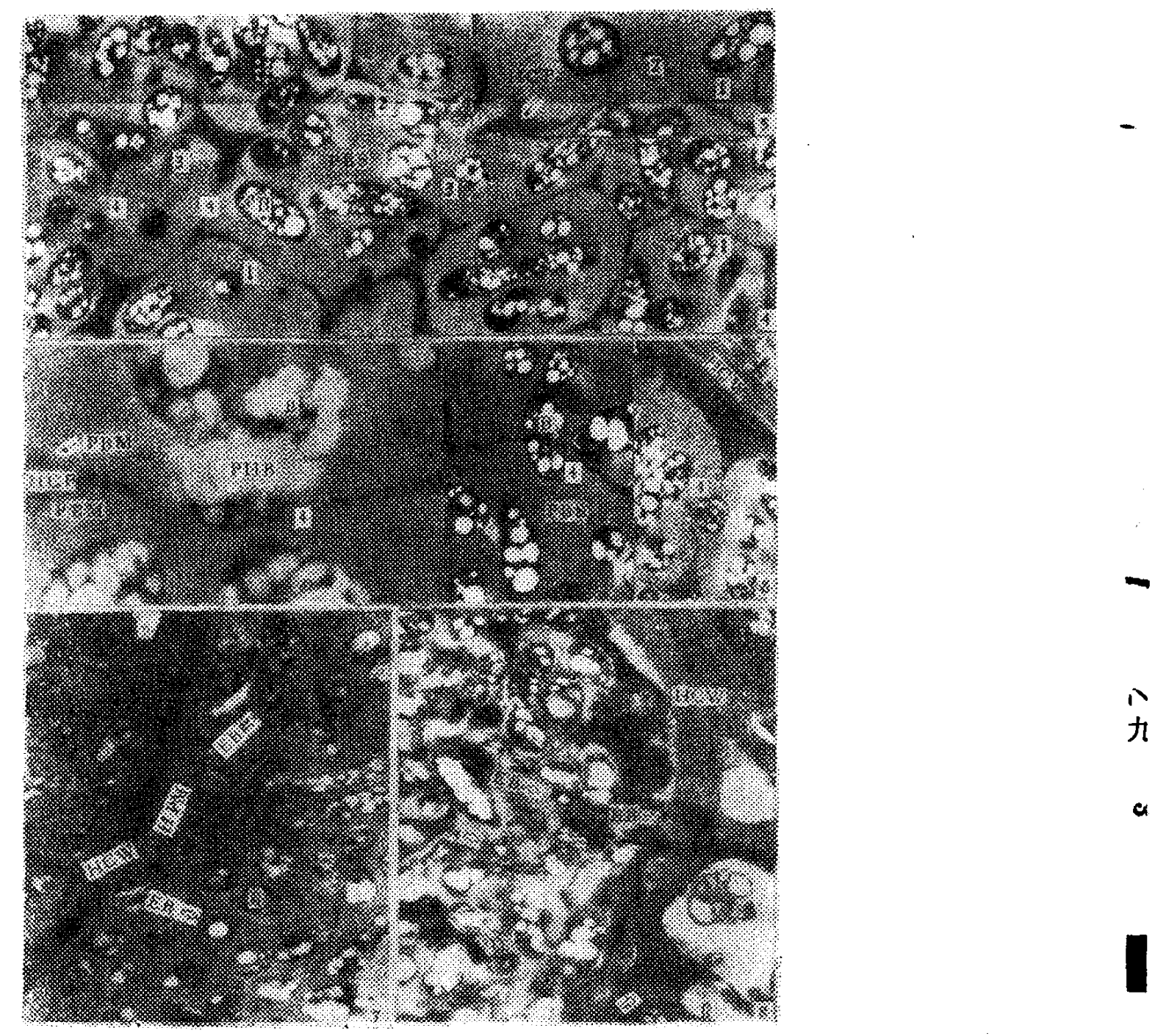

图 $4-8$

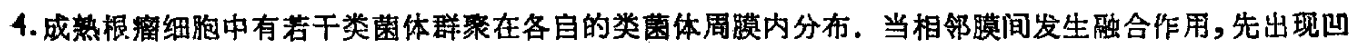
凸对位诺合, 可有“对称型”(左侧黑箭头 1) 或者“不对称型”(右侧白箭头 1) 的连络方式. 注意在一个膜 上, 不同边缘与相邻膜同时发生 $1,2 、 3 、 4$ 融合阶段的非同步反应. $\times 7,000 ; 5$. 两膜接触中絮密㙋近, 把

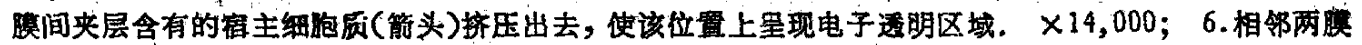
中间部位先融合穿通，随后由此不断地扩大融合范围，让类菌体能穿越此融合通道. 左图 $\times 28 ， 000$, 中

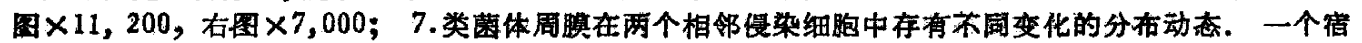
主细胞内的类曾体周膜保持完整; 另一个细胸内已开始出现解离变化. 无周膜包辜的少数几个类菌体裸 露分右于宿主细胸质中 (白箭头)..$\times 10 ; 500 ； 8$. 衰老类落体与周膜解离后, 见有几个小杆状细菌穿壁 离开宿主细胞(白箭头)。这时宿主侵染细胞质中, 出现电子密度高的数聚块状物质, 并且细胞壁上显现 有膨胀的松礼快态： $\times 7,000$.

图 4-6 为成熟类菌体电镜照片, 图 7-8 为衰老类菌体电镜炤片。其中图 1-2 为有刺金合欢, 图 3-8 为 苏门答腊全合欢. PHB. 聚 $\beta$-䍩基丁酸；EB. 裸露类菌体; HPM. 宿主质膜。其余图内英文缩写同图 1-3

的; 图 4 左侧 1 黑箭头又显示“对称型”的相做形式, 即两膜各自出现不同凹凹的伸缩, 与对位膜 构成交错镶族。

在这两膜挨合阶段, 从电镜上可看出夹层间充满着电子染色致密分右的宿主侵染细胞质, 说明它们不是马上就融合的.

（2）两膜紧密贴近: 进一步在膜间接触, 这些夹层中细胞质被挤压出去(图 5 中 HCP 分 
布在 1 与 2 分段上的不同比较)，把两膜彼此紧密贴近起来. 经电镜验证两膜边界清晰可辨 (图 4 和 5 中 2 阶段),在膜间仍留下微小的间隙,尚末达到真正融合.

（3）中间膜先穿通融合: 膜内物质流动和膜表面上分布不平衡. 最初融合的不是全膜, 而是始自膜中间部位，从融合点穿通两膜间隔,接着就不断地扩大了融合的范围(图 4 中 3 表 示). Gunning 在晼豆根瘤纵切片的研究也曾经发现类菌体周膜的中间先产生融合现象 ${ }^{[11]}$.

（4）哑呤状融合体出现: 当两膜中间融合穿通后,促进两边的细胞物质交换,通道也就逐 渐加宽,把两膜间连接成为哑呤状的融合体 (图 4 和 6 中 4 阶段). 与此同时,还可看到类菌体 细胞穿越此通道, 也就是由一个膜内转移向另一个膜的移位现象. 从图 6 中 4 可以看出,类菌 体的开始穿越(图 6 右示)、穿到通道口(图 6 左示)和已穿越过膜(图 6 中间示)这些生动的景 象.

（5）发展成为新的融合体: 伴随着融合膜的扩大变化,细胞质交换作用充分地进行,最后 发展到成为一个巨大近球状的新融合体, 到此就完成膜融合的全过程.

\section{3. 表老类菌体周膜解离动态}

根瘤衰老变化过程,引起类菌体与周膜解离 (图 7、8), 便失去原有电子透明区域的间隙。 在宿主细胞质中产生电子染色致密度高的凝聚块状物质,并逐渐移近到达细胞壁上.这时候的 细胞壁结构松弛并有肿胀现象,且在各分段壁上带着不同程度肿胀反应的变化(图 8). 另外, 宿主细胞里还出现裸露着的小杆状细菌. 它们不仅分布在宿主细胞质中, 而且还能穿过溶解 壁的中间层或朝向细胞间隙游走（图 8 中白箭头所示). 根据 Bassett 等报道大豆根瘤退化期: 间,类菌体周膜会发生自溶解离 ${ }^{[1]}$, 这一发现与本文上述现象相类似。

\section{讨 论}

根瘤菌侵入宿主豆科植物形成共生根瘤后, 它便在宿主细胞内发育成固氮类菌体. 同时由 宿主细胞质膜分化出类菌体周膜包业. 此膜 Bergersen 等首先在大豆根瘤中发现,称为包被膜 (membrane envelope $)^{[2]}$, 然后 Robertson 等在羽扇豆和大豆根瘤发现, 称为类菌体周膜 (Peribacter oid membrane $)^{[12,13]}$ 有关这方面的许多研究报告 ${ }^{[2,5,6,12,13]}$ 对类菌体周膜结构变 化, 很少 有具体的阐述. 1970 年 Gunning ${ }^{[11]}$ 运用高分辨率电镜 (16-26 万倍)研究豌豆根瘤, 由纵切 面看到两膜中间的内层, 有对称性分叉状的合并,他曾推断这类菌体周膜有融合的现象. 但他 又认为即使是膜融合也是少见的稀有现象,并且还是非常短暂的不连续的过程. 1981 年 Ne. wcomb 等 ${ }^{[7]}$ 在评述 Gunning 的工作时,也未能阐明此膜的亚显微结构. 而他们自己从绿豆根 瘤发育中, 只观察到类菌体周膜融合的遗迹 ${ }^{[3]}$, 即相当于本文叙述的第三个阶段. 也就是说当 两膜中间先行融合穿通后，再扩大此通道的同时还留着两边缘膜的痕迹. 可惜这些作者都未 能详细描述类菌体周膜融合的全部演变过程. 多年来有关此膜融合的研究报道甚少. 我们于 1983 年观察类菌体细胞结构时, 就发现苏门答腊金合欢根瘤细胞中类菌体周膜能自相融合. 1984 年又发现该类菌体周膜是在根瘤细菌发育早期和成熟期都会发生融合. 1985 年还发现 有刺金合欢的类菌体周膜，也有相似的融合作用．本文报道上述两种金合欢根瘤类菌体周膜 融合过程,并非是异常变化现象,它表现出五个动态阶段上的形态特征, 这是从电镜探讨而得 的首次报道.图 4-6 中,可分别看出类菌体细胞穿越融合膜一系列生动的景象.值得注意的是 在一个未成熟类菌体周膜或者成熟类菌体周膜上, 同样都可以有几处出现非同步融合阶段的 反应,正如图 4 中所示, 类菌体周膜与周围相邻膜接触中, 可分别呈现出 $1 、 2 、 3 、 4$ 多动态阶段 
的表现. 同时也可说明膜间融合力是不平衡的,因而使此膜的形态结构和大小变化都不一样， 有的可产生融合,有的就不产生融合;有的膜融合频率很高,有的则很低.

由于类菌体周膜融合作用增添了类菌体聚生数目的分布. 这可直接影响到共生细胞结构 与固氮功能间的相互关系. 据 Newcomb 等研究绿豆根瘤发育变化, 也认为类菌体周膜融合 的结果增加包㐮类菌体数目, 5-15 个或者是更多数目的出现 ${ }^{[6]}$.

其次,类菌体周膜在根瘤衰老过程中,也具有明显的形态结构变化. 成熟类菌体周膜呈现 疏松包裹, 具有宽阔的膜间隙区域. 当转变到衰老类菌体, 周膜便形成紧密包裹, 并大大减 缩膜间隙区域, 进一步再退化到类菌体周膜的解离. 当把无周膜包裹的裸露类菌体直接释放 到宿主细胞质中, 便显示出单独游离类菌体的分布状态（图 7、8）. 这种衰老过程似乎带有 一定顺序性演变 ${ }^{[9]}$, 这是过去光学显微镜所看不到的 ${ }^{[10]}$. 就共生细胞结构来说, 根瘤菌与宿 主细胞间的相互依存关系, 长期以来就未受到重视,尤其是有关固氮类菌体周膜融合与解离机 制尚需要进一步深人地探讨. 从类菌体细胞结构上可以看出, 只有在类菌体周膜包裹持续时 期,才能显示类菌体固氮作用功能;到了进人衰老阶段,类菌体周膜解离后,细胞共生结构将导 致崩溃, 随之也长失固氮功能。

当前在植物遗传工程的研究中,细胞融合是主要的研究手段之一,而细胞融合实质上就是 以细胞膜相互融合作为基础的. 今后应研究利用周膜融合力, 改善与强化固氮类菌体结构使 其达到最有效的组合形式,这在固氮生物工程上不能不说是很有价值的新线索.

致谢：刘利华、陈细法和陈方顺同志帮助电镜摄影及超薄切片工作，谨致谢意.

\section{参文 堿}

[1] Bassett, B., Goodman, R. N. and Novacky, A., Can. J. Microbiol., 23(1977), 573-582.

[ 2 ] Bergersen, F. J. and Briggs, M. J., J. Gen. Microbiol., 19(1958), 482-490.

[ 3 ] Dart, P. J. and Mercer, F. V., J. Bact., 85(1963), 951-952.

[ 4 ] Dart, P. J. and Mercer, F. V., J. Bact., 91(1966), 1314-1319.

[ 5 ] Goodchild, D. J. and Bergersen, F. J., J. Bact., 92(1966), 204-213.

[ 6 ] Newcomb, W. and Mclntyre, L., Can. J. Bot., 59(1981), 2478-2499.

[ 7 ] Newcomb, W., Int. Rev. Cyto. (Suppl.), 13(1981), 247-298.

[ 8 ] Sutton, W. D. in Nitrogen Fixation, Vol. 3, Legumes (Ed. Broughton, W. J.), Clarendon Press, Oxford, New York, 1983, 145-259.

[ 9 ] 吴以德、黄维南、卓仁松, 福建农学院学报, 14(1985), 3: 185-193.

[10] 吴以德、黄维南、张振玨、祭克强、嶚龙样，武夷科学, 1985, 5 .

[11] Gunning, B. E. S., J. Cell Sci, 7(1970), 307-317.

[12] Robertson, J. G., Lyttleton, P., Bllivant, S. and Granyston, G. F., J. Cell Sci., 30(1978), 129-149.

[13] Robertson, J. G., Lyttleton, P. and Tapper, B. A., in Nitrogen Fixation Research, Proceedings of the Sth International Symposium on Nitrogen Fixation (Eds. Veeger, C. and Newton, W. E.), Noordwijkerhout, Netherlands, 1984, 475-481. 